\title{
Raising Calves in the Dairy Period Without Antibiotics
}

\author{
Yu Fomichev* \\ Department of Biochemistry and Physiology of Agricultural Animals/ Laboratory of Chemical and Analytical Research, L.K. Ernst Federal Science Center for \\ Animal Husbandry, Russia
}

*Corresponding author: Yu Fomichev, Professor, Department of Biochemistry and Physiology of Agricultural Animals/ Laboratory of Chemical and Analytical Research, L.K. Ernst Federal Science Center for Animal Husbandry, Russia.
Received Date: January 13, 2020

Published Date: February 07, 2020

\section{Introduction}

The raising of healthy calves, both for the reproduction of the dairy herd and for the production of meat, is a fundamental link in realizing the genetically determined potential of animal productivity and has a significant impact on the economy of the dairy cattle breeding industry. The most common diseases of young animals are gastrointestinal and pulmonary infections, which are closely related to the physiological status of the neonatal period, characterized by functional instability in the work of many systems and increased vulnerability of the body, inadequate rhythms of blood circulation and respiration, digestion functions and body protection. The triggering principle of the disease can be stressful factors - improper and untimely feeding of newborns, poor-quality colostrum and giving it in a chilled state. As a result, withdrawal of calves, for example, due to diarrhea, can reach $30-50 \%$ or more of the number of births, and those who are ill are strongly behind in growth. It should be noted that both in the prevention and in the metaphylaxis of these diseases, the main means are antibiotics, which in addition to the therapeutic effect have a detrimental effect on the beneficial intestinal microflora, which inhibits the functional and physiological development of the gastrointestinal tract as a whole. In the formation of productive health, including nonspecific resistance and immunity of the calf's body, biologically active substances play an important role - regulators of homeostasis of natural origin, which, as a rule, are absent or have low bioavailability in synthetic diets. These substances include dihydroquercetin (DHQ) and arabinogalactan (AG).

DHQ is a bioflavonoid with a wide spectrum of biologicalaction: it regulates metabolic processes, has a positive effect on the functional state of the internal organs of the body, creates mechanisms to protect healthy body cells from pathologies caused by chemical poisoning, exposure to electromagnetic radiation and radiation, by neutralizing radical activity, viral and bacterial nature. It is non-toxic, harmless, has high activity at low concentrations, and is resistant to thermal and mechanical influences. It is recognized as a reference antioxidant and is widely used in medicine and the food industry [14] The introduction of DHQ in the diet of farm animals and poultry has a positive effect in immunodeficiency, bronchopulmonary pathology and impaired liver function, etc., which is usually the result of exposure to the body of adverse environmental factors and technologies inadequate to the physiology of farm animals. Due to capillary-protective and antioxidant properties of DHQ. the metabolism at the border of the cell and capillary is significantly improved and the antioxidant status of the body is corrected. Useful properties of DHQ are called pleiotropic, which are already evident in the first 1-2 months of receiving DHQ. AG is a complex natural water-soluble polysaccharide, widely used as the main component of biologically active additives intended for the prevention of cardiovascular, bronchopulmonary, infectious diseases, diabetes, liver diseases, maintaining a normal balance of the microflora of the gastrointestinal tract [5]. It is a nutrient medium for beneficial bacteria, extremely important to protect the gastric mucosa from pathogenic organisms. AG - a natural immunomodulator that significantly activates the body's protective cells, is a source of soluble dietary fiber necessary for the reliable functioning of the immune system. The use of hypertension in veterinary medicine is promising. Foods with the addition of AG maintain the level of bifidobacteria and lactobacilli in the gastrointestinal tract of animals, which improves nutritional efficiency, increases weight gain, and reduces the need for conventional antibiotics. The DHQ and AG used in these studies were obtained from Daurian larch (Larix dahurica Turez) of Ametis JSC [6]. 


\section{Materials and Methods}

Studies were carried out on calves of black-and-white breed in the conditions of the farm, where cases of disease of calves with bronchopulmonary pneumonia, diarrhoea, as well as cases of death were registered. For the study, two groups of calves (bulls and heifers) were selected with 10 heads each at the age of 10 days. One group was control, the other experienced. Calves of the experimental group were given a diet of DHQ at the rate of $1 \mathrm{mg}$ / kg live weight/ day together with water-soluble AG, which was included in the diet at the rate of $75 \mathrm{mg} / \mathrm{kg}$ live weight/day for 6 months. After calving, the calves were kept in individual cages and then transferred to groups of 5 heads. Feeding was carried out in accordance with the diet, which provided for the inclusion of starter feed, feed, hay, mineral premix, etc. in accordance with the physiological development and growth of calves. In general, the diet provides for heifers $450 \mathrm{~kg}$ of whole milk, $310 \mathrm{~kg}$ of whole milk substitute (WMS) feed $220 \mathrm{~kg}$, hay $220 \mathrm{~kg}$, feed mixes $400 \mathrm{~kg}$, mineral additive and salt. For bulls -whole milk $250 \mathrm{~kg}$, WMS $450 \mathrm{~kg}$. during the study period, antibiotics were not used. To monitor the health of calves and their development, blood samples were taken from the jugular vein at the age of 30,120, and 180 days. Hematological parameters of blood were determined on the $A B C$ VET analyzer (Horiba ABZ, France); - biochemical parameters of blood serum) on the automatic biochemical analyzer Chem Well (Awareness Tehnology, USA), Malon dialdehyde by reaction with 2-thiobarbituric acid; antioxidant activity of blood plasma by the rate of oxidation of the reduced form of 2,6-DHFIF; [7] the resistance of the organism calves was determined by lysozyme and bactericidal activity of blood serum [8] Microbiocenosis of the large intestine was studied in calves at the age of 60 days by the Cup method with the determination of groups of microorganisms. The research results were processed biometrically with the determination of the student-Fisher confidence criterion and using the Microsoft Office Excel 2010 computer program.

\section{The Results of Research and Discussion}

The inclusion of DHQ and AG in the calves ' diet in general had a positive effect on the daily exchange. In calves of the experimental group, the total protein content in the blood serum during the experimental period increased by $18.7 \%$ by the 4 th month, and by $29.0 \%$ by the 6th month in relation to its level at the age of 1 month. This increase is mainly due to the albumin fraction, which was higher on the 4 th month by $10 \%$, and on the 6 th by $9.5 \%$ relative to the original value. The difference in albumin content at the age of 4 months in relation to the control group was statistically significant at $\mathrm{P}<0.01$. This dynamics of changes in the content of total protein and its fractions due to age indicates the active development of anabolic processes in the body. The calves of the control group also showed an increase in the total protein content in the blood serum with age, but it was significantly lower and amounted to 9.7 and $20.5 \%$, respectively, at the age of 4 and 6 months, and was mainly associated with the globulin fraction. The albumin content in the blood serum at the age of 4 months in calves of this group in relation to the initial value decreased by $3.0 \%$, and at 6 months increased only by $1.95 \%$ (Table.1). Data on the content and dynamics of changes in total protein and its fractions in blood serum in connection with the age of calves of both groups are consistent with data on the content of free amine nitrogen (FAN) and urea. In calves of the control group, the serum FAN content was 4.42, 4.96 and $4.96 \mathrm{mmol} / \mathrm{l}$, respectively, at the age of 1,4 and 6 months, while in calves receiving DHQ and AG, its content was significantly lower and was equal to $1.13(\mathrm{P}<0.001), 1.68(\mathrm{P}<0.001)$ and 1.68 $\mathrm{mmol} / \mathrm{l}(\mathrm{P}<0.001)$, respectively, which may indicate a better use of nitrogenous substances in protein metabolism. There were also differences in the urea content and its dynamics of changes in blood serum due to age. In calves of the control group, the urea content at the age of 1 month was equal to $3.99 \mathrm{mmol} / \mathrm{l}$, by the 4 th it increased to $5.5 \mathrm{mmol} / \mathrm{l}$, and then decreased to $2.41 \mathrm{mmol} / \mathrm{l}$. in calves of the experimental group at the age of 1 month, the urea content in the blood serum was close to the control group, then it decreased to $2.57 \mathrm{mmol} / \mathrm{l}(\mathrm{P}<0.001)$ and remained at this level until the age of 6 months. These data indicate a lower process of deamination of amino acids and their better use in protein metabolism.

DHQ and AG also had a positive effect on carbohydrate-lipid metabolism. In calves of the experimental group, the serum glucose content at the age of 1 month was lower by $27.5 \%(\mathrm{P}<0.05)$ than in the control, but by the 4 th month, the provision of glucose for metabolic processes improved and its content increased to 5.06 $\mathrm{mmol} / \mathrm{l}(\mathrm{P}<0.05)$ compared to $4.0 \mathrm{mmol} / \mathrm{l}$ in the control. In the future, these indicators were compared and amounted to 5.75 and $5.68 \mathrm{mmol} / \mathrm{l}$, respectively, in calves of the experimental and control groups. Similar changes in relation to the age of calves occurred in the content of NEFA and cholesterol. In calves of the experimental group under the age of 4 months, the content of NEFA in the blood serum was higher by $26.8 \%$ and $19.4 \%(\mathrm{P}<0.01)$, which is associated with better energy supply of metabolic processes in this period of intensive growth. The content of cholesterol in the serum of calves of the experimental group at the age of 4 months was 2.32 mmol/l $(\mathrm{P}<0.01)$, which was higher than in the control group by $51.6 \%(\mathrm{P}<0.01)$. Phosphatase alkaline is an important indicator of the intensity and direction of mineral metabolism. In calves of the experimental group and its activity in the study period was significantly changed in that time, as it in control group was more stable and varied with age within 327,4-295,7 IU/l in calves of the experimental group and its activity has increased to 4 months of age by $42 \%$, which was higher than that of control by $26.6 \%$ and by the age of 6 months decreased by $35.3 \%$ and was lower than control by $7.2 \%$. Such dynamics of changes in the activity of phosphatase alkaline in calves of the experimental group may be associated with increased growth of bone tissue and its mineralization (Table 1).

The level of total bilirubin and transaminase activity in the blood serum are indicators of the functional state of the liver. The total bilirubin content in calves of the experimental group was lower than in control calves during the entire study period and its decrease was observed by the age of 6 months. The calves of the control group also had a decrease in its content at the age of 
4 months, but by the 6 th month there was a significant increase and amounted to $10.72 \mu \mathrm{mol} / \mathrm{l}$, which was higher than in the experimental group, almost 2 times $(\mathrm{P}<0.001)$, which indicates a higher solubility and cleavability of fats by the enzyme lipase, as well as the hepatoprotective effect of additives. Changes in the activity of aminotransaminases express the intensity of amino acid and energy metabolism, and in clinical and physiological terms-the state of the liver and cardiovascular system. It can be assumed that the differences between the control and the experimental group indicate a closer relationship between protein and carbohydrate metabolism. ALT activity by the $4^{\text {th }}$ month of the study increased in calves in the experimental group relative to the control group-by $13.71 \%$. The activity of AST in the $1^{\text {st }}$ month of research in calves of the experimental group was higher relative to the control group - by 7.04 , and on the 4 th decreased by $10.25 \%$. At the 6 th month of the study, these indicators were almost equal and did not have a significant difference but were higher than in the control by $12.6 \%$ (Table 1).

Table 1: Biochemical parameters of calves' blood serum.

\begin{tabular}{|c|c|c|}
\hline \multirow{2}{*}{ Parameters } & \multicolumn{2}{|c|}{ The Performance of the Group, $(\mathrm{M} \pm \mathrm{m})$} \\
\hline & Control & Experienced \\
\hline \multicolumn{3}{|c|}{ At the Age of 1 Month } \\
\hline Protein total, g/L & $60,95 \pm 1,05$ & $60,95 \pm 1,18$ \\
\hline Albumin, g/L & $25,75 \pm 0,48$ & $25,02 \pm 0,42$ \\
\hline Globulin total, $\mathrm{g} / \mathrm{L}$ & $35,20 \pm 1,39$ & $35,93 \pm 1,23$ \\
\hline A/G Ratio & $0,73 \pm 0,04$ & $0,70 \pm 0,02$ \\
\hline Urea, $\mathrm{mmol} / \mathrm{L}$ & $3,99 \pm 0,37$ & $4,10 \pm 0,43$ \\
\hline Free amine nitrogen, $\mathrm{mmol} / \mathrm{L}$ & $4,42 \pm 0,39$ & $1,13 \pm 0,2^{* * * *}$ \\
\hline Glucose, $\mathrm{mmol} / \mathrm{L}$ & $4,41 \pm 0,17$ & $3,2 \pm 0,26^{* * *}$ \\
\hline NEFA, mg/dL & $1,08 \pm 0,13$ & $1,37 \pm 0,06$ \\
\hline Cholesterol total, $\mathrm{mmol} / \mathrm{L}$ & $2,36 \pm 0,44$ & $1,87 \pm 0,21$ \\
\hline Phosphatase alkaline, $\mathrm{U} / \mathrm{L}$ & $327,4 \pm 55,7$ & $241,3 \pm 31,4$ \\
\hline Bilirubin total, $\mu \mathrm{mol} / \mathrm{L}$ & $7,55 \pm 0,8$ & $6,29 \pm 0,9$ \\
\hline ALT, U/L & $6,96 \pm 0,8$ & $6,74 \pm 0,52$ \\
\hline AST, U/L & $40,79 \pm 4,47$ & $43,66 \pm 2,16$ \\
\hline \multicolumn{3}{|c|}{ At the Age of 4 Months } \\
\hline Protein total, g/L & $66,9 \pm 1,33$ & $72,4 \pm 1,19^{* *}$ \\
\hline Albumin, g/L & $25,0 \pm 0,29$ & $27,5 \pm 0,64^{* * *}$ \\
\hline Globulin total, g/L & $41,9 \pm 1,56$ & $45,0 \pm 1,67$ \\
\hline A/G Ratio & $0,60 \pm 0,03$ & $0,61 \pm 0,03$ \\
\hline Urea, mmol/L & $5,5 \pm 0,32$ & $2,57 \pm 0,26 * * * *$ \\
\hline Free amine nitrogen, $\mathrm{mmol} / \mathrm{L}$ & $4,96 \pm 0,27$ & $1,68 \pm 1,48^{* * * *}$ \\
\hline Glucose, $\mathrm{mmol} / \mathrm{L}$ & $4,0 \pm 0,25$ & $5,06 \pm 0,35^{*}$ \\
\hline NEFA, mg/dL & $1,13 \pm 0,02$ & $1,35 \pm 0,05^{* * *}$ \\
\hline Cholesterol total, $\mathrm{mmol} / \mathrm{L}$ & $1,53 \pm 0,13$ & $2,32 \pm 0,16^{* * *}$ \\
\hline Phosphatase alkaline, U/L & $334,6 \pm 24,26$ & $423, \pm 25,6$ \\
\hline Bilirubin total, $\mu \mathrm{mol} / \mathrm{L}$ & $5,87 \pm 1,34$ & $5,73 \pm 0,94$ \\
\hline ALT, U/L & $22,6 \pm 0,28$ & $25,7 \pm 0,97^{* *}$ \\
\hline AST, U/L & $81,0 \pm 4,47$ & $72,7 \pm 1,72$ \\
\hline \multicolumn{3}{|c|}{ At the Age of 6 Months } \\
\hline Protein total, g/L & $73,42 \pm 3,69$ & $78,64 \pm 1,98$ \\
\hline Albumin, g/L & $26,07 \pm 0,83$ & $28,56 \pm 0,79$ \\
\hline Globulin total, g/L & $47,35 \pm 2,86$ & $50,07 \pm 2,77$ \\
\hline A/G Ratio & $0,55 \pm 0,05$ & $0,57 \pm 0,043$ \\
\hline Urea, mmol/L & $2,41 \pm 0,28$ & $2,53 \pm 0,189$ \\
\hline Free amine nitrogen, mmol/L & $4,96 \pm 0,27$ & $1,68 \pm 1,48^{* * * *}$ \\
\hline Glucose, mmol/L & $5,75 \pm 0,09$ & $5,68 \pm 0,24$ \\
\hline
\end{tabular}




\begin{tabular}{|c|c|c|}
\hline NEFA, $\mathrm{mg} / \mathrm{dL}$ & $1,86 \pm 0,07$ & $1,80 \pm 0,035$ \\
\hline Cholesterol total, $\mathrm{mmol} / \mathrm{L}$ & $2,62 \pm 0,27$ & $2,87 \pm 0,16$ \\
\hline Phosphatase alkaline, $\mathrm{L} / \mathrm{L}$ & $295,7 \pm 31,4$ & $274,5 \pm 21,8$ \\
\hline Bilirubin total, $\mu \mathrm{mol} / \mathrm{L}$ & $10,72 \pm 0,95$ & $5,45 \pm 0,13 * * * *$ \\
\hline ALT, $\mathrm{U} / \mathrm{L}$ & $29,24 \pm 0,16$ & $32,95 \pm 2,54$ \\
\hline AST, U/L & $56,0 \pm 10,87$ & $65,48 \pm 2,72$ \\
\hline
\end{tabular}

${ }^{*} \mathrm{P}<0,05:{ }^{* *} \mathrm{P}<0,02:{ }^{* * *} \mathrm{P}<0,01 ;{ }^{* * * *} \mathrm{P}<0,001$

Positive characteristic changes under the influence of DHQ with AG were observed in the state of antioxidant status of calves. Thus, the content of malonic dialdehyde in the blood of calves of the experimental group tended to decrease from 0.47 microns $/ 1$ in the first month to $0.43 \mu \mathrm{mol} / \mathrm{l}$ by the 6 th month, respectively, while the calves of the control group had a constant increase in the value of this indicator from 0.42 to $0.58 \mu \mathrm{mol} / \mathrm{l}(\mathrm{P}<0.01)$. At the same time, the calves of the experimental group had an increase in the antioxidant protection of the body, which was expressed in an increase in the antioxidant active (AOA) of blood plasma from 1.32 to $1.48 \mathrm{l} \times \mathrm{ml} 1 \times \min 1 \times 103$, while in the calves of the control group, the value of this indicator decreased from 1.27 to 1.25 $1 \times$ min-- $1 \times 10-3$ and was lower than in the calves of the experimental group $(\mathrm{P}<0.01)$. The acid number of blood serum in calves of all groups tended to increase. A more significant increase occurred in the calves of the control group, which amounted to $71.7 \%$ by the 6 th month of the study, while in the experimental group it was equal to $31.54 \%$. From the above data, it follows that calves receiving DHQ and AG had a lower concentration of lipid peroxidation products and an increased level of antioxidant protection. This indicates a decrease in lipoperoxidation processes and indicates the activation of cellular protective mechanisms against the harmful effects of free radicals (Table 2 ).

Table 2: Lipid peroxidation and antioxidant protection.

\begin{tabular}{|c|c|c|}
\hline \multirow{2}{*}{ Parameters } & \multicolumn{2}{|c|}{$\begin{array}{l}\text { The Performance of the Group, } \\
\qquad(\mathrm{M} \pm \mathrm{m})\end{array}$} \\
\hline & Control & Experienced \\
\hline \multicolumn{3}{|c|}{ At the Age of 1 Month } \\
\hline Acid number, KOH, mg/g & $2,16 \pm 0,26$ & $2,73 \pm 0.12$ \\
\hline Malonic dialdehyde, $\mu \mathrm{mol} / \mathrm{L}$ & $0,42 \pm 0,02$ & $0,47 \pm 0,01^{*}$ \\
\hline AOA of blood plasma, $1 \times \min ^{-1} \times 10^{-3}$ & $1,27 \pm 0,02$ & $1,32 \pm 0,015$ \\
\hline \multicolumn{3}{|c|}{ At the Age of 4 Months } \\
\hline Acid number, $\mathrm{KOH}, \mathrm{mg} / \mathrm{g}$ & $2,46 \pm 0,24$ & $2,69 \pm 0,10$ \\
\hline Malonic dialdehyde, $\mu \mathrm{mol} / \mathrm{L}$ & $0,5 \pm 0,01$ & $0,46 \pm 0,46^{* *}$ \\
\hline AOA of blood plasma, $1 \times \min ^{-1} \times 10^{-3}$ & $1,29 \pm 0,036$ & $1,35 \pm 0,019$ \\
\hline \multicolumn{3}{|c|}{ At the Age of 6 Months } \\
\hline Acid number, KOH, mg/g & $3,71 \pm 0,13$ & $3,59 \pm 0,067$ \\
\hline Malonic dialdehyde, $\mu \mathrm{mol} / \mathrm{L}$ & $0,58 \pm 0,02$ & $0,43 \pm 0,25^{* * *}$ \\
\hline AOA of blood plasma, $1 \times \min ^{-1} \times 10^{-3}$ & $1,25 \pm 0,05$ & $1,48 \pm 0,25^{* * *}$ \\
\hline
\end{tabular}

${ }^{*} \mathrm{P}<0,05:{ }^{* *} \mathrm{P}<0,02:{ }^{* * *} \mathrm{P}<0,01 ;{ }^{* * * *} \mathrm{P}<0,001$

The use of DHQ with AG in the diet of calves had a positive effect on morphological and hematological parameters of blood.
Thus, at the 1st month of research, the content of white blood cells in the experimental group was higher relative to the control group by $19.37 \%$ and by the 6 th month their content decreased relative to the control group by $49.56 \%$. this can be explained by the antiinflammatory activity of DHQ, due to its antioxidant effect and inhibitory effect against the enzymes produced during inflammation and subsequent inhibition of the production of inflammatory mediators. The red blood cell count tended to increase. At the 4th month of research in calves of the experimental group, their number increased relative to the control group by $29.16 \%$, and at the 6 th month by $7.72 \%$, which it had a positive effect on the hemoglobin content in the blood and the value of hematocrit (Table 3 ). According to the indicators of nonspecific resistance of calves of the experimental group positively differed from the control ones. Thus, the bacteriocidic activity blood serum (BABS) was higher at the 1 st month in the experimental group by $22.6 \%(\mathrm{P}<0.02)$, at the 4 th-by $32.8 \%$, and at the 6 th month by $16.8 \%(\mathrm{P}<0.05)$ relative to the control group. The level of lisocimic activity blood serum (LABS) also tended to increase in the experimental group: at the 1st month of research by $35.6 \%,(\mathrm{P}<0.05)$, at the 4 th by $56 \%$, and at the 6th month increased by $19.6 \%$ (Table 4). In the study of intestinal microbiocenosis, dysbacteriosis was established in both groups, due to a decrease in the number of lactobacilli and bifidobacteria. In the control group, there was a decrease in the number of E. coli with normal enzymatic activity, while in the experimental groups, these indicators were within the normal range. Cases of diarrhoea decreased and there was an improvement in the overall condition, as well as in the control group were identified colonization of coagulase-negative staphylococci, hemolytic E. coli, and yeast-like fungi of the genus Candida. Thus, this confirms the data that AG supports the normal balance of the microflora of the gastrointestinal tract, being a nutrient medium for beneficial bacteria (Table 5). The use of DHQ and AG in raising calves both in the dairy and post-dairy period, positively affected the dynamics of their growth, morbidity and safety. During the $1^{\text {st }}$ month after birth, the average daily gain in calves of the experimental group was $193 \mathrm{~g}$, which was higher than in the control group by $29.5 \%$. In the next two months, the increase was equal and amounted to $230 \mathrm{~g} /$ day in both groups. In the period from 3 to 6 months in the calves of the experimental group, the average daily increase was again higher than in the control group and amounted to $687 \mathrm{~g}$. In the control group of calves, two cases of the disease were noted: one in severe, the other in mild form with a safety of $90 \%$. In the experimental group, there was one case of mild disease with $100 \%$ safety of the livestock. 
Table 3: Morphological and hematological parameters of blood of calves.

\begin{tabular}{|c|c|c|}
\hline \multirow{2}{*}{ Parameters } & \multicolumn{2}{|c|}{ The Performance of the Group, $(\mathrm{M} \pm \mathrm{m})$} \\
\hline & Control & Experienced \\
\hline \multicolumn{3}{|c|}{ At the Age of 1 Month } \\
\hline Leukocytes, $10^{9} / \mathrm{L}$ & $8,93 \pm 1,23$ & $10,66 \pm 0,62$ \\
\hline Eritrocites, $10^{12} / \mathrm{L}$ & $7,03 \pm 0,75$ & $7,43 \pm 0,66$ \\
\hline Hemoglobin, g/L & $80,04 \pm 8,36$ & $82,0 \pm 6,41$ \\
\hline \multicolumn{3}{|c|}{ At the Age of 4 Months } \\
\hline Leukocytes, $10^{9} / \mathrm{L}$ & $11,15 \pm 1,09$ & $12,3 \pm 1,84$ \\
\hline Eritrocites, $10^{12} / \mathrm{L}$ & $7,68 \pm 0,69$ & $9,92 \pm 0,27^{* *}$ \\
\hline Hemoglobin, g/L & $107,3 \pm 6,2$ & $109,9 \pm 2,33$ \\
\hline \multicolumn{3}{|c|}{ At the Age of 6 Months } \\
\hline Leukocytes, $10^{9} / \mathrm{L}$ & $22,52 \pm 6,42$ & $11,36 \pm 0,66$ \\
\hline Eritrocites, $10^{12} / \mathrm{L}$ & $8,42 \pm 0,28$ & $9,07 \pm 0,167$ \\
\hline Hemoglobin, g/L & $100,8 \pm 6,83$ & $104,62 \pm 2,41$ \\
\hline
\end{tabular}

${ }^{*} \mathrm{P}<0,05:{ }^{* *} \mathrm{P}<0,02:{ }^{* * *} \mathrm{P}<0,01 ;{ }^{* * * *} \mathrm{P}<0,001$

Table 4: Indicators of pathogenetic resistance of calves.

\begin{tabular}{|c|c|c|c|}
\hline \multirow{2}{*}{ Age, months } & \multirow{2}{*}{ Indicators } & \multicolumn{2}{|c|}{ The performance of the Group, (M \pm m) } \\
\cline { 3 - 4 } & & Control & Experienced \\
\hline \multirow{2}{*}{1} & BABS $\%$ & $45,02 \pm 2,17$ & $55,2 \pm 1,53^{* *}$ \\
\cline { 2 - 4 } & LABS, $\mu \mathrm{g} / \mathrm{ml}$ & $120 \pm 8,3$ & $162,7 \pm 13,0^{*}$ \\
\hline \multirow{2}{*}{4} & BABS, $\%$ & $28,3 \pm 1,3$ & $37,6 \pm 4,6$ \\
\cline { 2 - 4 } & $\mathrm{LABS}, \mu \mathrm{g} / \mathrm{ml}$ & $75 \pm 20,6$ & $117 \pm 9,3$ \\
\hline \multirow{2}{*}{6} & $\mathrm{BABS}, \%$ & $67,3 \pm 0,62$ & $78,6 \pm 1,2^{*}$ \\
\cline { 2 - 4 } & $\mathrm{LABS}, \mu \mathrm{m} / \mathrm{ml}$ & $64,6 \pm 8,1$ & $77,3 \pm 15,3$ \\
\hline
\end{tabular}

${ }^{*} \mathrm{P}<0,05:{ }^{* *} \mathrm{P}<0,02:{ }^{* * *} \mathrm{P}<0,01 ;{ }^{* * * *} \mathrm{P}<0,001$

Table 5: Microbiocenosis of the large intestine of calves aged 60 days.

\begin{tabular}{|c|c|c|c|}
\hline Microflora & Norm, CFU/g & \multicolumn{2}{|c|}{ Groups } \\
\hline $\begin{array}{c}\text { E. coli with normal } \\
\text { enzymatic activity }\end{array}$ & $10^{7}-10^{9}$ & $6,8 \times 10^{5}$ & $2,9 \times 10^{8}$ \\
\hline Lactobacilli & $>10^{6}$ & $10^{4}$ & $10^{4}$ \\
\hline Bifidobacteria & $10^{9}-10^{10}$ & $3,4 \times 10^{7}$ & $4,0 \times 10^{7}$ \\
\hline Hemolytic E. coli & 0 & $1,9 \times 10^{8}$ & 0 \\
\hline $\begin{array}{c}\text { Staphylococci } \\
\text { coagulasenegative }\end{array}$ & $10^{4}-10^{6}$ & $4,8 \times 10^{7}$ & 0 \\
\hline $\begin{array}{c}\text { Yeast-like fungi of the } \\
\text { genus Candida }\end{array}$ & $<10^{2}$ & $1,4 \times 10^{7}$ & 0 \\
\hline
\end{tabular}

\section{Conclusion}

Thus, DHQ used in calves 'nutrition in combination with AG in the dairy period of growing in conditions of zoo hygienic distress fully revealed their biological properties, which provided a high level of antioxidant protection, the formation of microbiocenosis and intestinal immunity, correction and control of mineral homeostasis in the calves' body. As a result, there was a normalization and increase in the intensity of protein, nitrogen, lipid, carbohydrate, energy and mineral metabolism, improved the functional state of the liver and increased pathogenetic resistance, which in general had a positive impact on the formation of productive health, vitality and resistance of the body to the action of biotic and abiotic environmental factors, safety and average daily gain of calves. Positive results were obtained with the use of DHQ in the raising of broilers, including in conditions of high temperature [9], as well as in the raising of pigs with higher resistance to pre-slaughter stress [10].

\section{Acknowledgement}

None.

\section{Conflict of Interest}

No conflict of interest.

\section{References}

1. Fomichev Yu, Nikanova l, Lashin S (2016) The effectiveness of using dihydroquercetin (taxifolin) in animal husbandry, poultry and apiculture for prevention metabolic disorders, higher antioxidative capacity, better resistance and realization of a productive potential of organism. Journal of International Scientific Publications: Agricultural and Food 4(1000020): 140-159.

2. General information (2013) Literature and scientific articles for specialists and doctors.

3. Commission Implementing Decision (EU) (2017) Authorizing the placing on the market of taxifolin-rich extract as a novel food ingredient under Regulation (EC) No 258/97 of the European Parliament and of the Council. EFSA Journal 15(92): 4682.

4. Artemyeva OA, Pereselkova DA, Fomichev Yu P (2015) Biologically active drug as an alternative to the use of antibiotics against pathogenic microflora. Agricultural biology 4: 513-519.

5. Grieshop CM, Flickinger EA, Fahey GC (2002) Oral administration of arabinogalactan affects immune status and fecal microbial populations in dogs. Journl of Nutrition 132(3): 478-482.

6. Medvedev EN, Babkin VA, Ostroumova LA (2013) larch Arabinogalactanproperties and application prospects. Chemistry of plant raw materials, (review) 1:27-37

7. Kondrakhin IP (2004) Methods of veterinary clinical laboratory diagnostics. Moscow: Koloss, pp. 520.

8. Plyashchenko SI, Sidorov L (1979) Natural resistance of animal organism. Kolos, pp. 182.

9. Pirgozliev V, Wesbrook C, Woods S, Karagesili M, Karadas F, et al. (2018) Feeding dihydroquercetin to broiler chickens. British Poultry Science 5: 1-5.

10. Vladova-Vangelova DB, Balev DK, Ivanova SG, Nakev JL, Nikolova TI, et al. (2019) Improving the oxidative stability of pork by antioxidant type phytonutrients. 